\title{
Metabolites of Hypoxic Cardiomyocytes Induce the Migration of Cardiac Fibroblasts
}

\author{
Huairui Shia Xuehong Zhang ${ }^{b}$ Zekun He ${ }^{c}$ Zhiyong Wu ${ }^{b}$ Yushu Lia Liya Rao \\ anstitute of Cardiology, Union Hospital, Tongji Medical College, Huazhong University of Science and \\ Technology, Wuhan, ${ }^{b}$ The First Department of Cardiovascular, People's Hospital of Jiangxi Province, \\ Jiangxi, cFuzhou Medical College of Nanchang university, Nanchang, Jiangxi Province, China
}

\author{
Key Words \\ Cardiomyocytes $•$ Cardiac fibroblasts $\bullet$ Migration $•$ Hypoxia
}

\begin{abstract}
Background: The migration of cardiac fibroblasts to the infarct region plays a major role in the repair process after myocardial necrosis or damage. However, few studies investigated whether early hypoxia in cardiomyocytes induces the migration of cardiac fibroblasts. The purpose of this study was to assess the role of metabolites of early hypoxic cardiomyocytes in the induction of cardiac fibroblast migration. Methods: Neonatal rat heart tissue was digested with a mixture of trypsin and collagenase at an appropriate ratio. Cardiomyocytes and cardiac fibroblasts were cultured via differential adhesion. The cardiomyocyte cultures were subjected to hypoxia for $2,4,6,8,10$, and $12 \mathrm{~h}$. The supernatants of the cardiomyocyte cultures were collected to determine the differences in cardiac fibroblast migration induced by hypoxic cardiomyocyte metabolites at various time points using a Transwell apparatus. Meanwhile, ELISA was performed to measure TNF- $\alpha$, IL-1 $\beta$ and TGF- $\beta$ expression levels in the cardiomyocyte metabolites at various time points. Results: The metabolites of hypoxic cardiomyocytes significantly induced the migration of cardiac fibroblasts. The induction of cardiac fibroblast migration was significantly enhanced by cardiomyocyte metabolites in comparison to the control after 2, 4, and 6 h of hypoxia, and the effect was most significant after $2 \mathrm{~h}$. The expression levels of TNF- $\alpha$, IL-1 $\beta$, IL- 6 , and TGF- $\beta$ were substantially increased in the metabolites of cardiomyocytes, and neutralization with anti-TNF- $\alpha$ and anti-IL-1 $\beta$ antibodies markedly reduced the induction of cardiac fibroblast migration by the metabolites of hypoxic cardiomyocytes. Conclusion: The metabolites of early hypoxic cardiomyocytes can induce the migration of cardiac fibroblasts, and TNF- $\alpha$ and IL-1 $\beta$ may act as the initial chemotactic inducers.
\end{abstract}

H. Shi, X. Zhang and Z. He contributed equally to this work.

Liya Rao

KARGER 


\section{Introduction}

Cardiovascular diseases are a class of high-mortality diseases with concomitant changes in tissue structural, electrical and systolic functional remodeling. The pathological basis of most cardiovascular diseases is that cardiac extracellular matrix (ECM) production and degradation balance disorders result in the excessive deposition of ECM and ultimately cause cardiac fibrosis [1-4]. Cardiac fibroblasts are the most abundant cells in the heart, accounting for $70 \%$ of all heart cells, and play a pivotal role in the structural remodeling of cardiac tissue and the metabolic balance of cardiac ECM [5]. After myocardial necrosis or damage, a large number of inflammatory cytokines are released in local areas [6-11]. Cardiac fibroblasts migrate directionally by Induced these inflammatory cytokines, aggregate in necrotic or damaged areas, and achieve cardiac repair via substantial proliferation and ECM production. The directional migration of cardiac fibroblasts is a critical step in myocardial repair and cardiac structural remodeling. The inflammatory cytokines IL- $1 \beta$ and TNF- $\alpha$ can significantly increase the migration of cardiac fibroblasts $[12,13]$.

Hypoxia is currently recognized as an independent risk factor and a trigger of diseases in multiple systems, such as the digestive, respiratory, urinary, and cardiovascular systems [14-16]. In a hypoxic environment, the human body undergoes a series of changes in its metabolic pattern to adapt to hypoxia. Depending on its duration, hypoxia can be classified as acute or chronic hypoxia [17]. Sustained hypoxia occurs when the human body is transferred from an atmosphere containing $21 \%$ oxygen to an environment with $8-12 \%$ oxygen [18]. There are various causes and mechanisms of hypoxia induction. For instance, hypoxia in multiple systems can occur in some plateau regions and certain chronic pulmonary diseases, such as chronic obstructive pulmonary diseases and sleep apnea syndrome. Additionally, an imbalance of oxygen supply and consumption in the coronary system leads to single organconfined myocardial hypoxia. Hypoxia has been reported to cause ventricular fibrosis [19]. Early fetal hypoxia leads to remodeling of the cardiovascular system and causes cardiac fibrosis [20, 21]. Hypoxia can trigger the release of inflammatory cytokines; however, few studies have investigated whether cardiomyocyte hypoxia can induce the migration of cardiac fibroblasts. Therefore, the present study investigated whether the cardiomyocyte metabolites present after different durations of hypoxia could induce fibroblast migration.

\section{Materials and Methods}

\section{Cell Culture}

Primary cultures of neonatal cardiomyocytes and cardiac fibroblasts were isolated from day or two newborn by digestion and differential adhesion, as described previously. All procedures involving animals were performed under an NIH Guidelines approved protocol in accordance with institutional guidelines and Used of Laboratory Animals (Science and Technology Department of Hubei Province, China). Briefly, Removing the heart after alcohol disinfection thoracotomy and immediately placed in a Petri dish with cold phosphate-buffered saline (PBS). After washing three times with PBS, the heart cut $1 \mathrm{~mm}$ x $1 \mathrm{~mm} \times 1$ mm pieces. Discarded PBS was added $0.1 \%$ collagenase B, $0.25 \%$ trypsin and PBS digestive enzymes. The heart tissue digested 1 st digestion $10 \mathrm{~min}$ at $37^{\circ} \mathrm{C}$ water bath carve, the supernatant was discarded. The digestion was repeated six times for 4 min each time, the supernatant was collected with an equal volume of $10 \%$ fetal calf serum to terminate digestion, and centrifuged at 1,000 rpm for $10 \mathrm{~min}$, the supernatant was discarded, using 10\% fetal bovine serum suspended precipitate and seeded in $50 \mathrm{~mL}$ flasks, 37\% $\mathrm{O}_{2}, 5 \%$ $\mathrm{CO}_{2}$ incubator for $90 \mathrm{~min}$, collected the supernatant and added $0.1 \mathrm{mmol} / \mathrm{L}$ of Brdu to suppress the growth of the remaining fibroblasts, seeded in plates $5 \times 10^{5}$ cells / 6-well , 48h after medium exchange. Meanwhile flasks rinsed with PBS and purified fibroblast cells, 10\% FBS media was added to obtain primary fibroblasts, $3 \sim 4$ generations fibroblasts used in the experiment. 


\section{Cellular Physiology \\ \begin{tabular}{l|l|l} 
and Biochemistry 10.1159/000456531 & $\begin{array}{l}\text { () } 2017 \text { The Author(s). Published by S. Karger AG, Basel } \\
\text { www.karger.com/cpb }\end{array}$ \\
\hline Published onlIne: January 27, 2017
\end{tabular}}

Shi et al.: The Migration of Cardiac Fibroblast

\section{Cells Hypoxia}

Cardiomyocytes starved by incubating in medium containing 0.5\% BSA (serum free) for overnight , divided into two groups control group and hypoxia group. The fourth day, the control group was added to each well $1 \mathrm{~mL}$ by using an ordinary serum-free DMEM. Hypoxia group replaced with nitrogen equilibrated DMEM per well $1 \mathrm{~mL}$, the plates placed in prefilled with $1 \% \mathrm{O}_{2}$ and $5 \% \mathrm{CO}_{2}$, respectively hypoxia for $2 \mathrm{~h}$, $4 \mathrm{~h}$, $6 \mathrm{~h}, 8 \mathrm{~h}, 10 \mathrm{~h}, 12 \mathrm{~h}$, cardiomyocytes culture fluid were collected for the Transwell experiments.

\section{Cell Viability Studies}

We used the trypan blue exclusion assay to determine hypoxia cardiomyocytes viability. Briefly, we exposed cardiomyocytes to hypoxia for $2 \mathrm{~h}, 4 \mathrm{~h}, 6 \mathrm{~h}, 8 \mathrm{~h}, 10 \mathrm{~h}$ and $12 \mathrm{~h}$. Cell was added $0.4 \%$ trypan blue dye for 3-5 min, added coverslip, put in the high-powered microscope and counted the living cells (not trypan blue staining for live cells and staining for dead cells ). Results are expressed as the percentage of cells surviving from the total plated. We performed each experiment in duplicate at least five times.

\section{Cell migration assay}

Cardiac fibroblast migration was determined using modified Boyden chambers with 8.0 - $\mu$ m porous polycarbonate membrane inserts. Transwell upper and lower chambers were added $0.1 \mathrm{~mL}$ or $0.6 \mathrm{~mL} 0.1 \%$ BSA dampening for $12 \mathrm{~h}$. Cardiac fibroblast starved by incubating in medium containing $0.5 \%$ BSA (serum free) for overnight, the digestion resuspended adjust the cell density of $2 \times 10^{5}$ cells $/ \mathrm{mL}, 0.1 \mathrm{~mL}$ was added the upper chamber, the lower chamber were added $0.6 \mathrm{~mL}$ the metabolites from hypoxia of cardiomyocytes at different time points, and placed $1 \% \mathrm{O}_{2}, 5 \% \mathrm{CO}_{2}$ at $37{ }^{\circ} \mathrm{C}$ incubator for $12 \mathrm{~h}$. After $12 \mathrm{~h}$ of experimental treatment, removing the membrane used $4 \%$ paraformaldehyde for $10 \mathrm{~min}$, the chamber were washed with PBS. Nonmigrated cells remaining on the upper face of the membrane were mechanically removed with a PBS-soaked swab. The membranes were detached from the chambers, air dried, and mounted on glass slides. We used Crystal Violet Staining Solution staining to the upper chamber. Migrated cells were visualized and counted with microscope, 5 randomly selected microscopic visual field $(\times 400)$ cells were averaged (number / HP), each experiment was repeated five times.

\section{Measurements of cytokines}

Cardiomyocytes placed in $1 \% \mathrm{O}_{2}$ and $5 \% \mathrm{CO}_{2}$ Hypoxic incubator respectively for $2 \mathrm{~h}, 4 \mathrm{~h}, 6 \mathrm{~h}, 8 \mathrm{~h}, 10 \mathrm{~h}$, $12 \mathrm{~h}$.The metabolites of hypoxic cardiomyocytes were collected and kept frozen at $-80^{\circ} \mathrm{C}$ until the cytokine levels were determined by ELISA assays, according to the manufacturer's instructions. Mouse TNF- $\alpha$, IL$1 \beta$, IL- 6 and TGF- $\beta$ were measured using mouse ELISA KIT (R \& D Systems) in strict accordance with the instructions of the test procedure.

\section{Statistical Analysis}

All data was first evaluated for normal distribution using the Kolmogorov-Smirnov test. Results are expressed as the means \pm SEMs when normally distributed. One-way ANOVA was used for multiple comparisons between $\geq 3$ groups followed by the Holm-Sidak test when data were normally distributed and group variances were equal. When group data were not normally distributed or if group variances were unequal, the Kruskal-Wallis test followed by the Dunn posthoc test was used. P-values $<0.05$ were considered statistically significant. All statistical analyses were performed using SPSS software (version 17.0, SPSS Inc, Chicago, IL)

\section{Results}

Effects of hypoxic cardiomyocytes on fibroblast migration

After different periods of hypoxia, cardiomyocyte metabolites induced varying numbers of fibroblasts to migrate to the lower chamber: $38.00 \pm 2.52$ fibroblasts after $2 \mathrm{~h}, 36.00 \pm 2.26$ fibroblasts after $4 \mathrm{~h}, 34.00 \pm 5.21$ fibroblasts after $6 \mathrm{~h}, 28.00 \pm 3.13$ fibroblasts after $8 \mathrm{~h}, 18.0$ \pm 7.210 fibroblasts after $10 \mathrm{~h}$, and $15.00 \pm 1.25$ fibroblasts after $12 \mathrm{~h}$ (Fig. $1 \mathrm{~A})$. The number of fibroblasts in the control group was $12.00 \pm 1.25(\mathrm{p}<0.01)$, and significant differences were found between groups (Fig. 1B). The effect of hypoxia on the chemotaxis of myocardial 


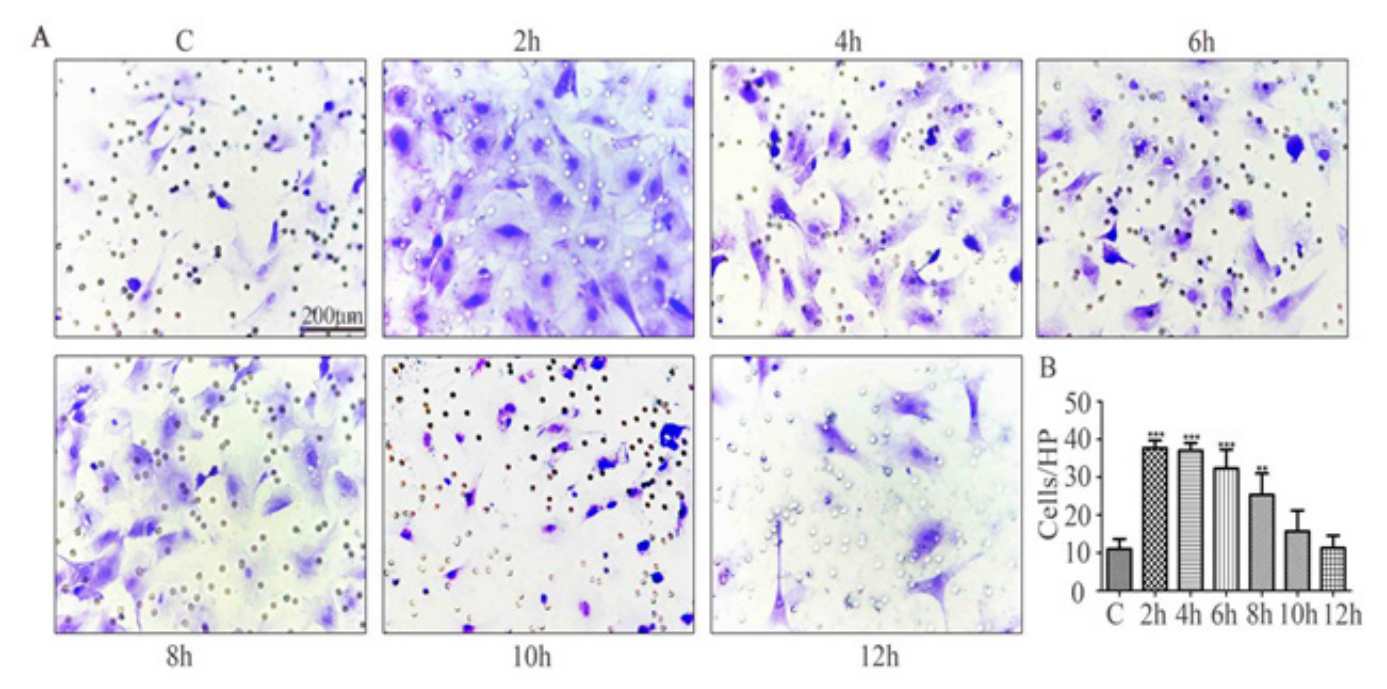

Fig. 1. The metabolites of hypoxic cardiomyocytes can induce the migration of cardiac fibroblasts. (A) Cardiac fibroblast migration was determined using modified Boyden chambers with 8.0 - $\mu$ m porous polycarbonate membrane inserts. upper chamber was added $0.1 \mathrm{~mL}$ the cardiac fibroblasts, the lower chamber were added $0.6 \mathrm{~mL}$ the metabolites from hypoxia of cardiomyocytes at different time points, and placed $1 \% \mathrm{O}_{2}$, $5 \% \mathrm{CO}_{2}$ at $37{ }^{\circ} \mathrm{C}$ incubator for $12 \mathrm{~h}$. Representative images of Crystal Violet Staining Solution staining of the upper chamber from the different treatment groups. (B) Quantitative analysis of the the migration of cardiac fibroblasts. Migrated cells were visualized and counted with microscope, 5 randomly selected microscopic visual field $(\times 400)$ cells were averaged (number / HP), each experiment was repeated five times. The data are expressed as the means $\pm \mathrm{SEM}$. One-way ANOVA followed by the Holm-Sidak test, ${ }^{*} \mathrm{P} \leq 0.05$; ${ }^{* *} \mathrm{P} \leq 0.01$; $* * * \mathrm{P} \leq 0.001$.

fibroblasts was most significant after $2 \mathrm{~h}$. The chemotaxis of myocardial fibroblasts was markedly attenuated and tended to be suppressed after $8 \mathrm{~h}$.

Expression of inflammatory cytokines in cardiomyocyte metabolites

To determine the mechanism by which hypoxic cardiomyocyte metabolites promote the migration of cardiac fibroblasts, we used an ELISA kit to assay related metabolic factors in the metabolites of hypoxic cardiomyocytes. The results showed that TNF- $\alpha$, IL-1 $1 \beta$, IL- 6 , and TGF- $\beta$ expression levels were markedly increased in the metabolites of hypoxic cardiomyocytes in comparison to the control (Fig. 2A-D). Specifically, TNF- $\alpha$ and IL-1 $\beta$ secretion began to increase significantly after $2 \mathrm{~h}$, TGF- $\beta$ levels increased substantially after $8 \mathrm{~h}$ and peaked after $12 \mathrm{~h}$, and a significant increase in IL-6 occurred after $4 \mathrm{~h}$. Significant differences were observed between groups $(\mathrm{p}<0.01)$. These results suggest that the metabolites of hypoxic cardiomyocytes can promote the migration of cardiac fibroblasts, which may be related to the increased secretion of the inflammatory cytokines TNF- $\alpha$ and IL-1 $\beta$.

\section{Effect of hypoxia on the activity of cardiomyocytes}

The cardiomyocytes were placed in a hypoxic chamber and treated for a predetermined period. The activity of the cardiomyocytes was assayed after hypoxia via a trypan blue exclusion test, according to the following equation: Cell activity $=$ the number of active cells / the number of total cells $\times 100$. The experimental data showed that no significant changes in cell activity occurred during hypoxia in comparison to the control group (Fig. 3A).

\section{Neutralization of inflammatory cytokines}

To assess the effects of anti-TNF- $\alpha$ and anti-IL- $1 \beta$ antibodies, we added $10 \mu \mathrm{g} / \mathrm{ml}$ of antiTNF- $\alpha$ and anti-IL-1 $\beta$ antibodies or an antibody isotype control for $4 \mathrm{~h}$ of pretreatment before

\section{KARGER}


Fig. 2. The metabolites of hypoxic cardiomyocytes can effect expression of inflammatory cytokines. Cardiomyocytes placed in prefilled with $1 \% \mathrm{O}_{2}$ and $5 \% \quad \mathrm{CO}_{2}$, respectively hypoxia for $2 \mathrm{~h}$, $4 \mathrm{~h}, 6 \mathrm{~h}, 8 \mathrm{~h}, 10 \mathrm{~h}, 12 \mathrm{~h}$, The metabolites of hypoxic cardiomyocytes were collected, the cytokine levels were determined by ELISA assays(AD). Each experiment was repeated five times. The data are expressed as the means \pm SEM. One-way ANOVA followed by the Holm-Sidak test, $\quad * \mathrm{P} \leq 0.05 ; \quad * * \mathrm{P} \leq 0.01$; $* * * \mathrm{P} \leq 0.001$.
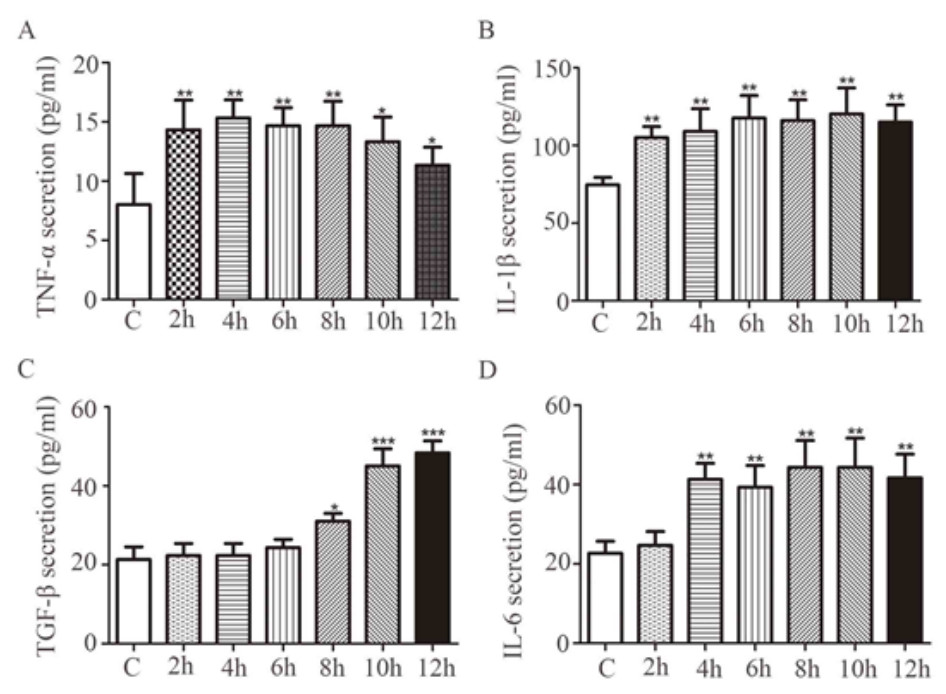

Fig. 3. Effect of hypoxia on the activity of cardiomyocytes, the cardiomyocytes were placed in a hypoxic chamber treated for a predetermined period. The activity of the cardiomyocytes was assayed by trypan blue exclusion test (A). To determine the effects of antiTNF- $\alpha$ and anti-IL-1 $\beta$ antibodies, we added $10 \mu \mathrm{g} / \mathrm{ml}$ of anti-TNF- $\alpha$ and anti-IL-1 $\beta$ antibodies or an antibody isotype control for $4 \mathrm{~h}$ of pretreatment before hypoxia. The TNF- $\alpha$ and IL-1 $\beta$ ex-

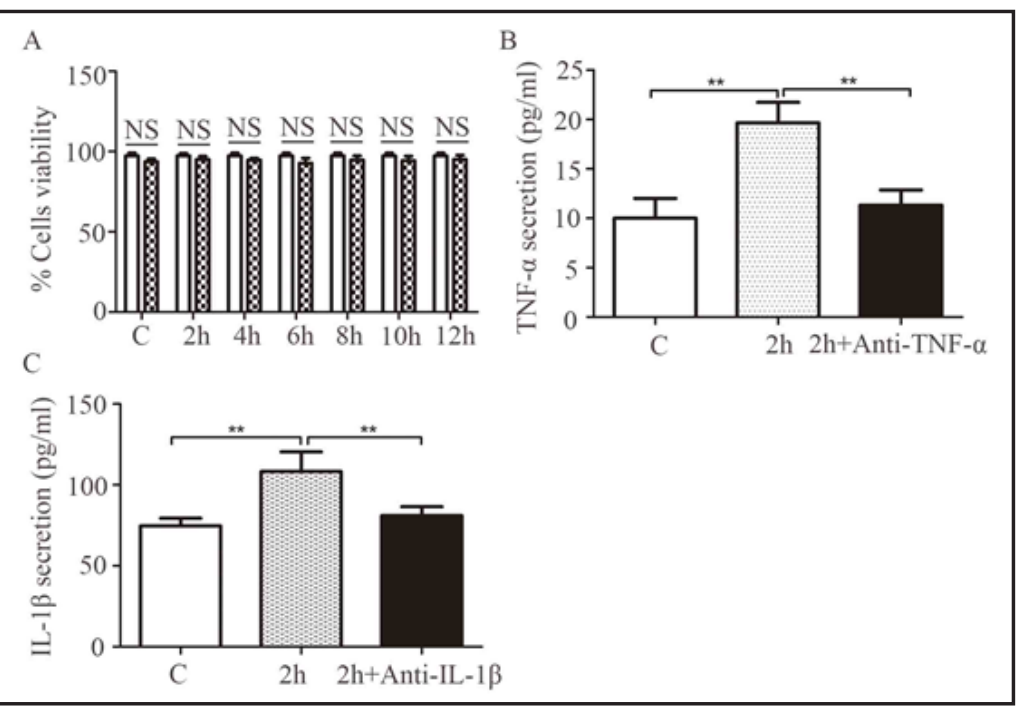
pression levels in the metabolites were then determined using an ELISA kit. Each experiment was repeated five times. The data are expressed as the means \pm SEM. One-way ANOVA followed by the Holm-Sidak test, ${ }^{*} \mathrm{P} \leq 0.05 ; * * \mathrm{P} \leq 0.01 ;{ }^{* * *} \mathrm{P} \leq 0.001$.

hypoxia. The TNF- $\alpha$ and IL-1 $\beta$ expression levels in the metabolites were then determined using an ELISA kit. The results showed that the anti-TNF- $\alpha$ and anti-IL-1 $\beta$ antibodies markedly lowered the TNF- $\alpha$ and IL-1 $\beta$ levels in the metabolites of hypoxic cardiomyocytes (Fig. 3B-C).

Effect of the partial neutralization of inflammatory cytokines on the migration of cardiac fibroblasts

To further illustrate the primary cause of cardiac fibroblast migration, we added $10 \mu \mathrm{g} / \mathrm{ml}$ of anti-TNF- $\alpha$ and anti-IL-1 $\beta$ antibodies or an antibody isotype control for 4 $\mathrm{h}$ of pretreatment before placing the cardiomyocytes in a hypoxic chamber for $2 \mathrm{~h}$. The metabolites were then collected and used to conduct the migration experiment. The results showed that the anti-IL-1 $\beta$ and anti-TNF- $\alpha$ antibodies significantly inhibited the migration of 


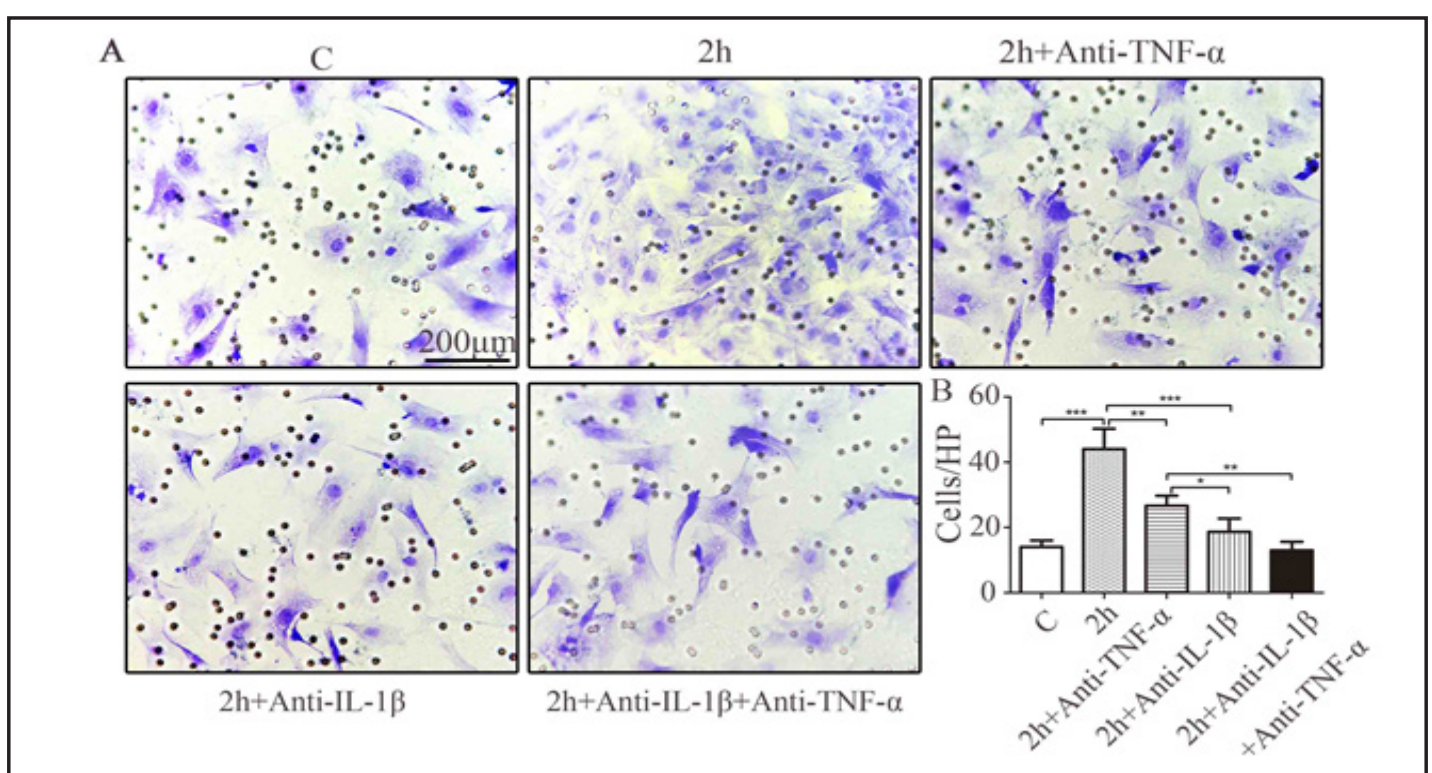

Fig. 4. Effect of the partial neutralization of inflammatory cytokines on the migration of cardiac fibroblasts. To further illustrate the primary cause of cardiac fibroblast migration, we added $10 \mu \mathrm{g} / \mathrm{ml}$ of anti-TNF- $\alpha$ and anti-IL-1 $\beta$ antibodies or an antibody isotype control for $4 \mathrm{~h}$ of pretreatment before placing the cardiomyocytes in a hypoxic chamber for $2 \mathrm{~h}$. The metabolites were then collected and used to conduct the migration experiment. Cardiac fibroblast migration was determined using modified Boyden chambers (A). (B) Quantitative analysis of the the migration of cardiac fibroblasts. Migrated cells were visualized and counted with microscope, 5 randomly selected microscopic visual field $(\times 400)$ cells were averaged (number / HP), each experiment was repeated five times. The data are expressed as the means \pm SEM. One-way ANOVA followed by the Holm-Sidak test, ${ }^{*} \mathrm{P} \leq 0.05 ;{ }^{* *} \mathrm{P} \leq 0.01$; ${ }^{* *} \mathrm{P} \leq 0.001$.

fibroblasts (Fig. 4A); the inhibitory effect was most obvious in the anti-IL-1 $\beta$ (Fig. 4B). These results indicate that IL-1 $\beta$ and TNF- $\alpha$ may be the main factors that trigger the migration of cardiac fibroblasts, with IL-1 $\beta$ playing a leading role.

\section{Discussion}

The present study showed that the metabolites of hypoxic cardiomyocytes could induce the migration of fibroblasts. After different periods of hypoxia, the cardiomyocyte metabolites exhibited distinctly different abilities to induce fibroblast migration. The cardiomyocyte metabolites exhibited the strongest ability to induce fibroblast migration after $2 \mathrm{~h}$ of hypoxia. In addition, the levels of relevant inflammatory cytokines (IL-1 $\beta$ and TNF- $\alpha$ ) were significantly increased in the metabolites of hypoxic cardiomyocytes. The neutralization of IL-1 $\beta$ and TNF- $\alpha$ in the metabolites of hypoxic cardiomyocytes could significantly inhibit the migration of cardiac fibroblasts.

Many factors can lead to cardiac functional and structural remodeling, which further result in abnormal myocardial function and induce a series of mortality and disability outcomes (e.g., heart failure and arrhythmias). Damage repair is a mechanism for body self-maintenance that is necessary to maintain tissue, organ, and system functions. In this repair mechanism, cardiac fibroblasts are the key functional unit; the migration of cardiac fibroblasts to the damaged site is the first step and a critical step in cardiac self-repair [2226]. Hypoxia is an independent risk factor for cardiovascular disease, the developmental stage of many diseases is closely related to hypoxia [27-29]. Our experiments showed that the metabolites of hypoxic cardiomyocytes could induce the migration of cardiac 
fibroblasts. This finding indicates that cardiomyocytes respond rapidly to hypoxia during the metabolic process and that metabolic changes occur in a short period of time. Meanwhile, cardiomyocytes constantly adjust their metabolism during exposure to different periods of hypoxia, thereby leading to regulatory changes in the induction of fibroblast migration. These changes caused significant differences in the number of fibroblasts that migrated after different periods of hypoxia. Cardiomyocyte hypoxia can cause an inflammatory response and promote the release of a large number of inflammatory cytokines [30, 31]. One study reported that cardiomyocytes produce a large amount of IL-6 after exposure to hypoxic conditions for $4 \mathrm{~h}$ [32], which is consistent with our results. Our experiment also showed that IL-6 levels were markedly increased in the metabolites of hypoxic cardiomyocytes. Although the study only observed a single time period, the employed hypoxic myocardium technique and the time window of inflammatory cytokine production were encompassed within the observation time of the experiment. However, this issue raises a logical contradiction with respect to the time window and the observed fibroblast migration-inducing capacity, as the ability to induce fibroblast migration was strongest after $2 \mathrm{~h}$ of hypoxia. Thus, the data do not support IL- 6 as the leading factor for the induction of fibroblast migration. In addition, other studies have shown that the inflammatory cytokine IL- 6 has a very weak ability to induce fibroblast migration [12]. This observation suggests that other factors might have played an earlier and stronger role in inducing fibroblast migration in the present study. Different hypoxia-induced pathologies are associated with the inflammatory response. The migration of cardiac fibroblasts is induced primarily by inflammatory cytokines. IL- $1 \beta$ has been shown to induce the migration of fibroblasts, and the migration capacity of IL-1 $\beta$ induced cells is approximately 20 times that of control cells. The capacity TNF- $\alpha$-induced cells is relatively weak and five times that of control cells. Clinical trials have shown that IL-1 $\beta$ and TNF- $\alpha$ expression is significantly increased in the plasma of patients with acute myocardial infarction; these two cytokines play an important role in myocardial damage and functional disorders $[33,34]$. Meanwhile, TNF- $\alpha$ synthesis is increased when the myocardium is subjected to a certain type of pressure change, while no fixed expression is observed under normal circumstances [35]. TNF- $\alpha$, which is an inflammatory cytokine derived from multiple cell types, plays a strong role in the induction of cardiac fibroblasts. In our experiment, we found that after $2 \mathrm{~h}$ of hypoxia, the levels of the inflammatory cytokines IL-1 $\beta$ and TNF- $\alpha$ were significantly increased in the metabolites of cardiomyocytes. We used anti-IL-1 $\beta$ and anti-TNF- $\alpha$ antibodies to neutralize IL-1 $\beta$ and TNF- $\alpha$ in the metabolites of hypoxic cardiomyocytes, which significantly inhibited the migration of cardiac fibroblasts. The antiIL-1 $\beta$ antibody inhibited the number of migrating cells more significantly than the antiTNF- $\alpha$ antibody after $2 \mathrm{~h}$ of hypoxia, which is consistent with results from previous studies. Meanwhile, the inhibition observed after blocking IL-1 $\beta$ and TNF- $\alpha$ was most significant. Our experimental results indicate that IL- $1 \beta$ and TNF- $\alpha$ play a major role in the induction of cardiac fibroblast migration by the metabolites of hypoxic cardiomyocytes. The inhibition of IL-1 $\beta$ and TNF- $\alpha$ secretion in cardiomyocytes can markedly block the migration of cardiac fibroblasts. IL-1 $\beta$ and TNF- $\alpha$ expression was significantly higher in the cardiomyocytes after $2 \mathrm{~h}$ of hypoxia than in the control group. This observation suggests that IL-1 $\beta$ and TNF- $\alpha$ are significantly increased before myocardial damage and necrosis. In hypoxic cardiomyocytes, a portion of the cardiac fibroblasts had migrated, and the migration of cardiac fibroblasts occurred prior to myocardial damage and necrosis.

Another phenomenon observed in this study is that with an extended duration of hypoxia, the supernatant of the cardiomyocytes showed a significantly reduced, rather than a progressively enhanced, ability to induce fibroblast migration. TGF- $\beta$, which is an anti-inflammatory cytokine, is significantly increased during myocardial infarction and plays an important role in late cardiac repair and remodeling. The results showed that TGF- $\beta$ could significantly inhibit the migration of cardiac fibroblasts. Our study found that TGF- $\beta$ levels were significantly increased in the metabolites of cardiomyocytes after $8 \mathrm{~h}$ of hypoxia. This finding indicates that the reduction of late cardiac fibroblast migration may be related to the elevated levels of the metabolite TGF- $\beta$.

\section{KARGER}




\section{Cellular Physiology Cell Physiol Biochem 2017;41:413-421

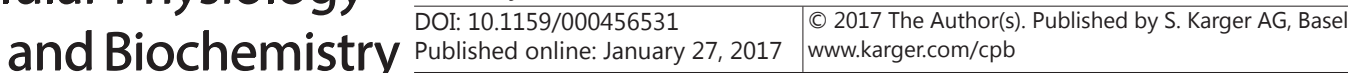

Shi et al.: The Migration of Cardiac Fibroblast

In summary, our experiments proved that the early metabolites of hypoxic cardiomyocytes could significantly induce the migration of cardiac fibroblasts. This finding indicates that the migration of cardiac fibroblasts may occur prior to myocardial damage and necrosis. Significantly increased levels of the inflammatory cytokines IL-1 $\beta$ and TNF- $\alpha$ in the hypoxic metabolites are the main factors by which cardiomyocyte hypoxia induces fibroblast migration.

\section{Acknowledgements}

This work was supported by grant ( The National Science Foundation of Hubei Province of China No (201060938361-04).

\section{Disclosure Statement}

The authors declare that there are no conflicts of interest.

\section{References}

1 Bonnans C, Chou J, Werb Z: Remodelling the extracellular matrix in development and disease. Nat Rev Mol Cell Biol 2014;15:786-801.

-2 Weber KT: Targeting pathological remodeling: Concepts of cardioprotection and reparation. Circulation 2000;102:1342-1345.

3 Lee RT, Lammerding J: Signaling pathways that influence extracellular remodeling. J Card Fail 2002;8:S339343.

4 Zhao X, Wang K, Liao Y, Zeng Q, Li Y, Hu F, Liu Y, Meng K, Qian C, Zhang Q Guan H, Feng K, Zhou Y, Du Y, Chen Z: MicroRNA-101a inhibits cardiac fibrosis induced by hypoxia via targeting TGF $\beta$ RI on cardiac fibroblasts. Cell Physiol Biochem 2015;35:213-226.

-5 Porter KE, Turner NA: Cardiac fibroblasts: At the heart of myocardial remodeling. Pharmacol Ther 2009;123:255-278.

6 Fang L, Moore XL, Dart AM, Wang LM: Systemic inflammatory response following acute myocardial infarction. J Geriatr Cardiol 2015;12:305-312.

7 Dinarello CA: A clinical perspective of il-1beta as the gatekeeper of inflammation. Eur J Immunol 2011;41:1203-1217.

8 Valgimigli M, Ceconi C, Malagutti P, Merli E, Soukhomovskaia O, Francolini G, Cicchitelli G, Olivares A, Parrinello G, Percoco G, Guardigli G, Mele D, Pirani R, Ferrari R: Tumor necrosis factor-alpha receptor 1 is a major predictor of mortality and new-onset heart failure in patients with acute myocardial infarction: The cytokine-activation and long-term prognosis in myocardial infarction (c-alpha) study. Circulation 2005;111:863-870.

-9 Biasucci LM, Liuzzo G, Fantuzzi G, Caligiuri G, Rebuzzi AG, Ginnetti F, Dinarello CA, Maseri A: Increasing levels of interleukin (il)-1ra and il-6 during the first 2 days of hospitalization in unstable angina are associated with increased risk of in-hospital coronary events. Circulation 1999;99:2079-2084.

10 Orn S, Ueland T, Manhenke C, Sandanger O, Godang K, Yndestad A, Mollnes TE, Dickstein K, Aukrust P: Increased interleukin-1 beta levels are associated with left ventricular hypertrophy and remodelling following acute st segment elevation myocardial infarction treated by primary percutaneous coronary intervention. J Intern Med 2012;272:267-276.

11 Andrie RP, Becher UM, Frommold R, Tiyerili V, Schrickel JW, Nickenig G, Schwab JO: Interleukin-6 is the strongest predictor of 30-day mortality in patients with cardiogenic shock due to myocardial infarction. Crit Care 2012;16:R152.

12 Mitchell MD, Laird RE, Brown RD, Long CS: Il-1beta stimulates rat cardiac fibroblast migration via map kinase pathways. Am J Physiol Heart Circ Physiol 2007;292:H1139-1147. 


\section{Cellular Physiology Cell Physiol Biochem 2017;41:413-421

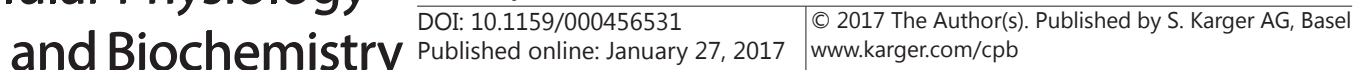

13 Brown RD, Jones GM, Laird RE, Hudson P, Long CS: Cytokines regulate matrix metalloproteinases and migration in cardiac fibroblasts. Biochem Biophys Res Commun 2007;362:200-205.

14 Yu X, Li T, Liu X, Yu H, Hao Z, Chen Y, Zhang C, Liu Y, Li Q, Mao M, Zhu D. Modulation of Pulmonary Vascular Remodeling in Hypoxia: Role of 15-LOX-2/15-HETE-MAPKs Pathway. Cell Physiol Biochem 2015;35:20792097.

15 Eltzschig HK, Carmeliet P: Hypoxia and inflammation. N Engl J Med 2011;364:656-665.

-16 Liu Y, Cui Y, Shi M, Zhang Q, Wang Q, Chen X. Deferoxamine promotes MDA-MB-231 cell migration and invasion through increased ROS-dependent HIF-1 $\alpha$ accumulation. Cell Physiol Biochem 2014;33:1036-1046.

-17 Estrada KD, Chesler NC: Collagen-related gene and protein expression changes in the lung in response to chronic hypoxia. Biomech Model Mechanobiol 2009;8:263-272.

18 McAdams-DeMarco MA, Maynard JW, Baer AN, Coresh J: Hypertension and the risk of incident gout in a population-based study: The atherosclerosis risk in communities cohort. J Clin Hypertens 2012;14:675679.

19 Oh C, Dong Y, Liu H, Thompson LP: Intrauterine hypoxia upregulates proinflammatory cytokines and matrix metalloproteinases in fetal guinea pig hearts. Am J Obstet Gynecol 2008;199:78 e71-76.

20 Iacobazzi D, Garaeva I, Albertario A, Cherif M, Angelini GD, Caputo M, Ghorbel MT: Protein Phosphatase 1 Beta is Modulated by Chronic Hypoxia and Involved in the Angiogenic Endothelial Cell Migration. Cell Physiol Biochem 2015;36:384-94.

21 Tong W, Zhang L: Fetal hypoxia and programming of matrix metalloproteinases. Drug Discov Today 2012;17:124-134.

22 Beltrami AP, Urbanek K, Kajstura J, Yan SM, Finato N, Bussani R, Nadal-Ginard B, Silvestri F, Leri A, Beltrami CA, Anversa P: Evidence that human cardiac myocytes divide after myocardial infarction. N Engl J Med 2001;344:1750-1757.

-23 MacKenna D, Summerour SR, Villarreal FJ: Role of mechanical factors in modulating cardiac fibroblast function and extracellular matrix synthesis. Cardiovasc Res 2000;46:257-263.

24 Camelliti P, Green CR, LeGrice I, Kohl P: Fibroblast network in rabbit sinoatrial node: Structural and functional identification of homogeneous and heterogeneous cell coupling. Circ Res 2004;94:828-835.

25 Sun Y, Kiani MF, Postlethwaite AE, Weber KT: Infarct scar as living tissue. Basic Res Cardiol 2002;97:343347.

26 Sun Y, Weber KT: Infarct scar: A dynamic tissue. Cardiovasc Res 2000;46:250-256.

27 Dumitrascu R, Heitmann J, Seeger W, Weissmann N, Schulz R: Obstructive sleep apnea, oxidative stress and cardiovascular disease: Lessons from animal studies. Oxid Med Cell Longev 2013:234631.

28 Rossi VA, Stradling JR, Kohler M: Effects of obstructive sleep apnoea on heart rhythm. Eur Respir J 2013;41:1439-1451.

-29 Eisele HJ, Markart P, Schulz R: Obstructive sleep apnea, oxidative stress, and cardiovascular disease: Evidence from human studies. Oxid Med Cell Longev 2015;2015:608438.

30 Yu X, Deng L, Wang D, Li N, Chen X, Cheng X, Yuan J, Gao X, Liao M, Wang M, Liao Y: Mechanism of tnf-alpha autocrine effects in hypoxic cardiomyocytes: Initiated by hypoxia inducible factor 1 alpha, presented by exosomes. J Mol Cell Cardiol 2012;53:848-857.

- 31 Wu J, Stefaniak J, Hafner C, Schramel JP, Kaun C, Wojta J, Ullrich R, Tretter VE, Markstaller K, Klein KU: Intermittent hypoxia causes inflammation and injury to human adult cardiac myocytes. Anesth Analg 2016;122:373-380.

-32 Yamauchi-Takihara K, Ihara Y, Ogata A, Yoshizaki K, Azuma J, Kishimoto T: Hypoxic stress induces cardiac myocyte-derived interleukin-6. Circulation 1995;91:1520-1524.

33 Levine B, Kalman J, Mayer L, Fillit HM, Packer M: Elevated circulating levels of tumor necrosis factor in severe chronic heart failure. N Engl J Med 1990;323:236-241.

34 Li D, Zhao L, Liu M, Du X, Ding W, Zhang J, Mehta JL: Kinetics of tumor necrosis factor alpha in plasma and the cardioprotective effect of a monoclonal antibody to tumor necrosis factor alpha in acute myocardial infarction. Am Heart J 1999;137:1145-1152.

-35 Kapadia S, Lee J, Torre-Amione G, Birdsall HH, Ma TS, Mann DL: Tumor necrosis factor-alpha gene and protein expression in adult feline myocardium after endotoxin administration. J Clin Invest 1995;96:10421052. 